\title{
Inulanolide A as a new dual inhibitor of NFAT1-MDM2 pathway for breast cancer therapy
}

\author{
Jiang-Jiang Qin ${ }^{1,2, *}$, Wei Wang ${ }^{1,2, *}$, Sushanta Sarkar ${ }^{1}$, Sukesh Voruganti ${ }^{1}$, Rajesh \\ Agarwal $^{3,4}$, Ruiwen Zhang ${ }^{1,2}$ \\ ${ }^{1}$ Department of Pharmaceutical Sciences, School of Pharmacy, Texas Tech University Health Sciences Center, Amarillo, TX \\ 79106, USA \\ ${ }^{2}$ Cancer Biology Center, School of Pharmacy, Texas Tech University Health Sciences Center, Amarillo, TX 79106, USA \\ ${ }^{3}$ Department of Pharmaceutical Sciences, Skaggs School of Pharmacy and Pharmaceutical Sciences, University of Colorado \\ Denver, Aurora, CO 80045, USA \\ ${ }^{4}$ University of Colorado Cancer Center, University of Colorado Denver, Aurora, CO 80045, USA \\ *These authors contributed equally to this work
}

Correspondence to: Ruiwen Zhang, e-mail: ruiwen.zhang@ttuhsc.edu Wei Wang, e-mail: wwei.wang@ttuhsc.edu

Keywords: Inulanolide A, NFAT1-MDM2 pathway, p53-independent, breast cancer orthotopic tumor model, metastasis

Received: January 27, 2016

Accepted: March 31, 2016

Published: April 20, 2016

\section{ABSTRACT}

The transcription factor NFAT1 and the oncogene MDM2 have crucial roles in breast cancer development, progression, and metastasis. We have recently discovered that NFAT1 activates MDM2 expression. Here, we identified a small molecule (named Inulanolide A) that dually inhibited both NFAT1 and MDM2 in breast cancer cells in vitro and in vivo. Unlike conventional MDM2 inhibitors, Inulanolide A (InuA) exerted its selective anticancer activity in both p53-dependent and -independent manners. InuA decreased cell proliferation and induced $\mathrm{G2} / \mathrm{M}$ phase arrest and apoptosis in breast cancer cells; it also led to a decrease in MDM2, NFAT1 and proteins associated with cell proliferation, and an increase in apoptotic signal related proteins. In a mouse orthotopic model, JapA suppressed tumor growth and lung metastasis without host toxicity. Thus, InuA is a novel NFAT1 and MDM2 dual targeting agent and may be a clinical candidate for breast cancer therapy. This study also validates the effectiveness of dually targeting NFAT1 and MDM2 in breast cancer.

\section{INTRODUCTION}

Breast cancer remains a major global health challenge [1-3]. The development of targeted therapies, including estrogen receptor (ER) modulators and human epidermal growth factor receptor 2 (HER2) antagonists, has improved the mortality of this disease $[4,5]$. Despite these recent clinical advances, intrinsic and acquired resistance to these therapies is still common. Some subtypes of breast cancer, such as triple negative breast cancer (TNBC), cannot benefit from the existing targeted therapies due to the intrinsic lack of molecular targets and their highly aggressive nature [6-9]. Therefore, developing effective and safe therapy for advanced breast cancer is a highly unmet medical need.

Mouse Double Minute 2 (MDM2) promotes cancer cell proliferation and cell cycle progression, inhibits DNA damage response, reduces apoptosis, and stimulates metastasis [10-12]. The MDM2 oncogene is genetically amplified and/or overexpressed in breast cancer patients [13-15] and is positively associated with poor prognosis and high incidence of metastasis [16-20]. Therefore, this multifaceted oncogene has been suggested as a promising molecular target for breast cancer therapy. Several targeting strategies have been developed to inhibit MDM2 and its activity, leading to the discovery of a number of MDM2 inhibitors [21-28]. We have recently demonstrated that the transcription factor NFAT1 transactivates MDM2, independent of p53 [29]. NFAT1 is aberrantly activated and overexpressed in breast cancer cells and promotes breast cancer development and progression [30-32]. Therefore, dually targeting MDM2 and NFAT1 could be a novel and effective approach to breast cancer therapy. 
We have recently proposed to develop dual inhibitors of NFAT1-MDM2 pathway and discovered a novel class of naturally occurring dimeric sesquiterpenoids, including the lead compounds JapA [26, 33] and Inulanolide A (InuA). JapA has been demonstrated as a potent and specific dual NFAT1-MDM2 inhibitor and has shown excellent anticancer activity in vitro and in vivo [26, 33]. As for every new drug investigation, there is no guarantee that one compound will be the clinical lead for future clinical studies. Therefore, we have selected several backup compounds. In addition, to further determine the efficacy and safety profiles of this class of natural NFAT1-MDM2 dual inhibitors and to explore the underlying mechanisms of action and structureactivity relationship (SAR), it is necessary to evaluate InuA and other candidates, which have different chemical structures but show similar activities. The present study was designed to investigate the anticancer efficacy of InuA and its molecular mechanisms of action in vitro and in vivo. In the initial screening for in vitro cytotoxicity of InuA, breast cancer cells exhibited high sensitivity to this compound. Therefore, we utilized breast cancer models for further evaluation of this compound. Our results demonstrate the therapeutic potential of targeting NFAT1-MDM2 pathway and provide new insights into MDM2 targeting strategies, suggesting that InuA may be a novel therapeutic agent for the treatment and prevention of human breast cancer.

\section{RESULTS}

\section{InuA exhibits selective cytotoxicity toward different types of cancer cells, with minimal effects on normal cell growth}

InuA was first tested for its effects on cell growth in two normal cell lines and 20 cancer cell lines representing nine types of human cancer (breast, prostate, lung, pancreatic, colon, ovarian, and liver cancer, sarcoma, and glioblastoma). After exposure of cells to various concentrations of InuA $(0$ to $50 \mu \mathrm{M})$ for $72 \mathrm{~h}$, the cell viability and $\mathrm{IC}_{50}$ values were determined using the MTT method. InuA exhibited a broad cytotoxicity spectrum $\left(\mathrm{IC}_{50}\right.$ values from 0.9 to $10.0 \mu \mathrm{M}$ ) against human cancer cells. Among this, breast cancer MCF7 (p53 wild-type), MCF7 p53 knockdown (KD), MDA-MB-231 (p53 mutant), and MDA-MB-468 (p53 mutant) cells exhibited strong sensitivity to InuA treatment, with the $\mathrm{IC}_{50}$ values of 2.4, 3.7, 4.1, and $0.9 \mu \mathrm{M}$, respectively (Figure 1). Most importantly, in comparison to cancer cells, the normal HEK293 and MCF10A cells were much less sensitive to InuA, suggesting that this compound has selective cytotoxicity against cancer cells (Figure 1). Interestingly, HCT116 p53 $3^{-/}$cells $\left(\mathrm{IC}_{50}=10.0 \mu \mathrm{M}\right)$ and MCF7 p53 KD cells $\left(\mathrm{IC}_{50}=3.7 \mu \mathrm{M}\right)$ had higher $\mathrm{IC}_{50}$ values than their parent cells (4.9 and $2.4 \mu \mathrm{M}$, respectively), indicating that the anticancer effects of InuA might not be totally p53-indepenent.

\section{InuA exerts in vitro anti-breast cancer activity}

As shown in Figure 2A, InuA inhibited the proliferation of both MCF7 and MDA-MB-231 cells in a concentration-dependent manner, regardless of the p53 status. Similarly, InuA induced apoptosis in both breast cancer cell lines in concentration-dependent and p53independent manners (Figure 2B). InuA treatment also caused cell cycle arrest at G2/M phase in both cell lines (Figure 2C), with the initial effective concentration at $2.5 \mu \mathrm{M}$. We further examined the effects of InuA on breast cancer cell migration and invasion. As shown in Figure 2D, the control MDA-MB-231 cells migrated into almost all of the wound area by $24 \mathrm{~h}$, whereas InuA significantly inhibited the cell migration in a concentration-dependent manner. Similarly, InuA at the sublethal concentrations significantly prevented the invasion of MDA-MB-231 cells (Figure 2E).

\section{InuA suppresses tumor growth and lung metastasis in nude mice bearing MDA-MB-231 orthotopic tumors}

We further investigated the in vivo efficacy of InuA in the MDA-MB-231 orthotopic model of human breast cancer. The compound was given by intraperitoneal injection at $30 \mathrm{mg} / \mathrm{kg} / \mathrm{d}, 5 \mathrm{~d} / \mathrm{wk}$ for 24 days. As shown in Figures $3 \mathrm{~A}$ and $3 \mathrm{~B}$, InuA treatment significantly inhibited the tumor growth by $84 \%(P<0.01)$. However, the compound did not affect the average body weights of the mice in comparison to that of control mice, indicating that there was no obvious host toxicity during the treatment period (Figure $3 \mathrm{C}$ ). At the termination of the experiments, all mice were autopsied for assessment of the metastatic lesions in various organs. The results showed that 9 out of 10 control mice developed metastatic lesions in the lungs, while InuA treatment decreased the incidence of lung metastasis to 2/10 (Figure 3D). Lungs and other major organs (liver, kidneys, spleen, heart, and brain) were dissected for histological examinations, confirming the inhibition of lung metastasis (Figure 3E). In addition, no abnormalities were observed in other organs from these mice, suggesting the absence of any host toxicity.

\section{InuA inhibits NFAT1-MDM2 pathway in vitro and in vivo}

The effects of InuA on NFAT1-MDM2 pathway were first investigated in MCF7 and MDA-MB-231 breast cancer cells. As shown in Figure 4A, InuA downregulated the expression of NFAT1 and MDM2 in both cell lines and activated the expression of wild-type p53 in MCF7 cells. However, no significant changes were observed in mutant p53 in MDA-MB-231 cells. To further investigate the molecular mechanisms responsible for the anticancer activity of InuA, we evaluated its effects on the expression of proteins involved in cell cycle progression, apoptosis, and 
DNA damage response. As shown in Figures 4B and 4C, InuA upregulated the expression of p21 and Bax, induced the cleavage of PARP, and reduced the expression of $\mathrm{Cdk} 2$, Cdk4, Cdk6, Cyclin D1, Cyclin E, c-Myc, and Bcl2 in both breast cancer cell lines. The compound also inhibited the expression of ATR, resulted in the phosphorylation of Chk1 at Ser317, Chk2 at Thr68, wild-type p53 at Ser15, and H2AX at Ser139 in breast cancer cells (Figure 4D). Next, we examined the protein expression in MDA-MB-231 orthotopic tumors by immunohistochemical staining, TUNEL assay (Figure 5A), and Western blotting assay (Figure 5B). The similar results were obtained in InuAtreated tumors as those observed in vitro.

\section{Knockdown of NFAT1 and MDM2 reduces the anticancer activity of InuA}

To demonstrate the importance of NFAT1-MDM2 pathway in InuA's anticancer activity, we compared the effects of InuA on inducible MDM2 KD MCF7 cells

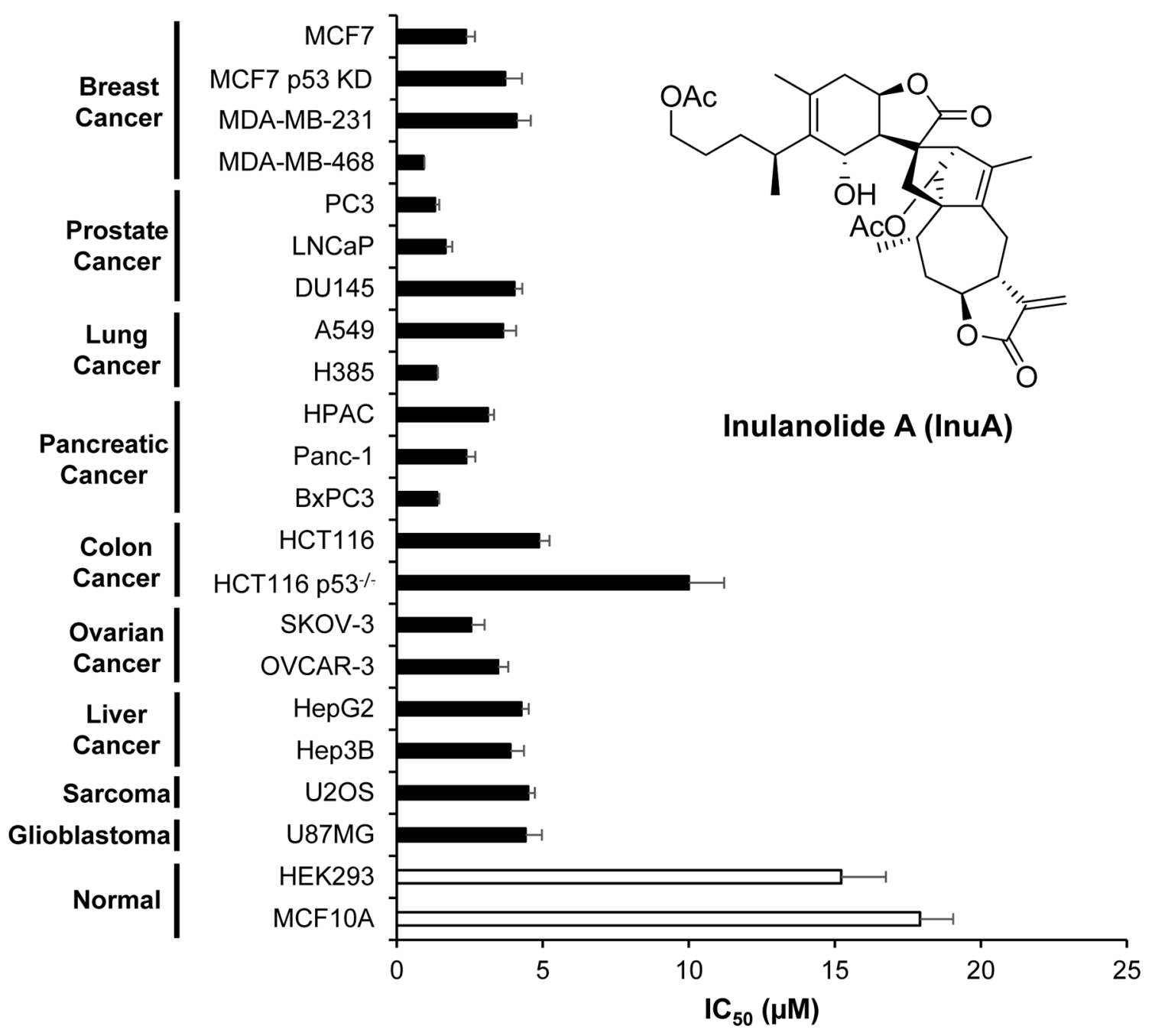

Figure 1: Cytotoxicity of InuA against various normal and cancer cell lines. Various normal and cancer cell lines were treated with InuA $(0-50 \mu \mathrm{M})$ for $72 \mathrm{~h}$. The cell viability and $\mathrm{IC}_{50}$ values were then determined using MTT assays. All assays were performed in triplicate and repeated three times. MCF7 p53 KD, MCF7 p53 knockdown; HCT116 p53 ${ }^{-/}$, HCT116 p53 knockout. with their parent cells. As shown in Figures 6A and 6B, tetracycline (Tet)-induced MDM2 KD inhibited cell growth and reduced the inhibitory effect of InuA on cell viability. In MDA-MB-231 cells, the transient transfection of MDM2 siRNA resulted in MDM2 KD, which decreased the cytotoxicity of InuA against cancer cells (Figures 6C and 6D). We also compared the cytotoxicity of InuA against parent and NFAT1 KD cells. As shown in Figures 7A-7D, the transient transfection of NFAT1 siRNA caused NFAT1 KD in both MCF7 and MDA-MB-231 cell lines, which further decreased the NFAT1-activated MDM2 expression and reduced the effects of InuA on cell viability. Taken together, these results indicated a critical role of NFAT1MDM2 pathway in the InuA-induced cell death in breast cancer cells.

\section{DISCUSSION}

In the present study, we evaluated the anticancer efficacy of a new dual NFAT1-MDM2 inhibitor InuA 
and examined the possible molecular mechanisms for its activities in preclinical models of human breast cancer in vitro and in vivo. We have demonstrated several important points in the present study. First, InuA exhibited a potent cell growth-inhibition activity in vitro in a wide spectrum of human cancer cell lines, with minimal cytotoxicity against normal cells. Second, InuA inhibited breast cancer cell proliferation and induced cell cycle arrest at G2/M phase and apoptosis in vitro, in concentration-dependent and p53-independent manners. Third, InuA suppressed the growth of orthotopic tumors in mice, without inducing any host toxicity. Fourth, InuA inhibited cell migration and invasion in vitro and prevented tumor metastasis to lungs in vivo. Finally, InuA inhibited the MDM2, NFAT1 and proteins associated with cell proliferation, and activated apoptotic signal related proteins
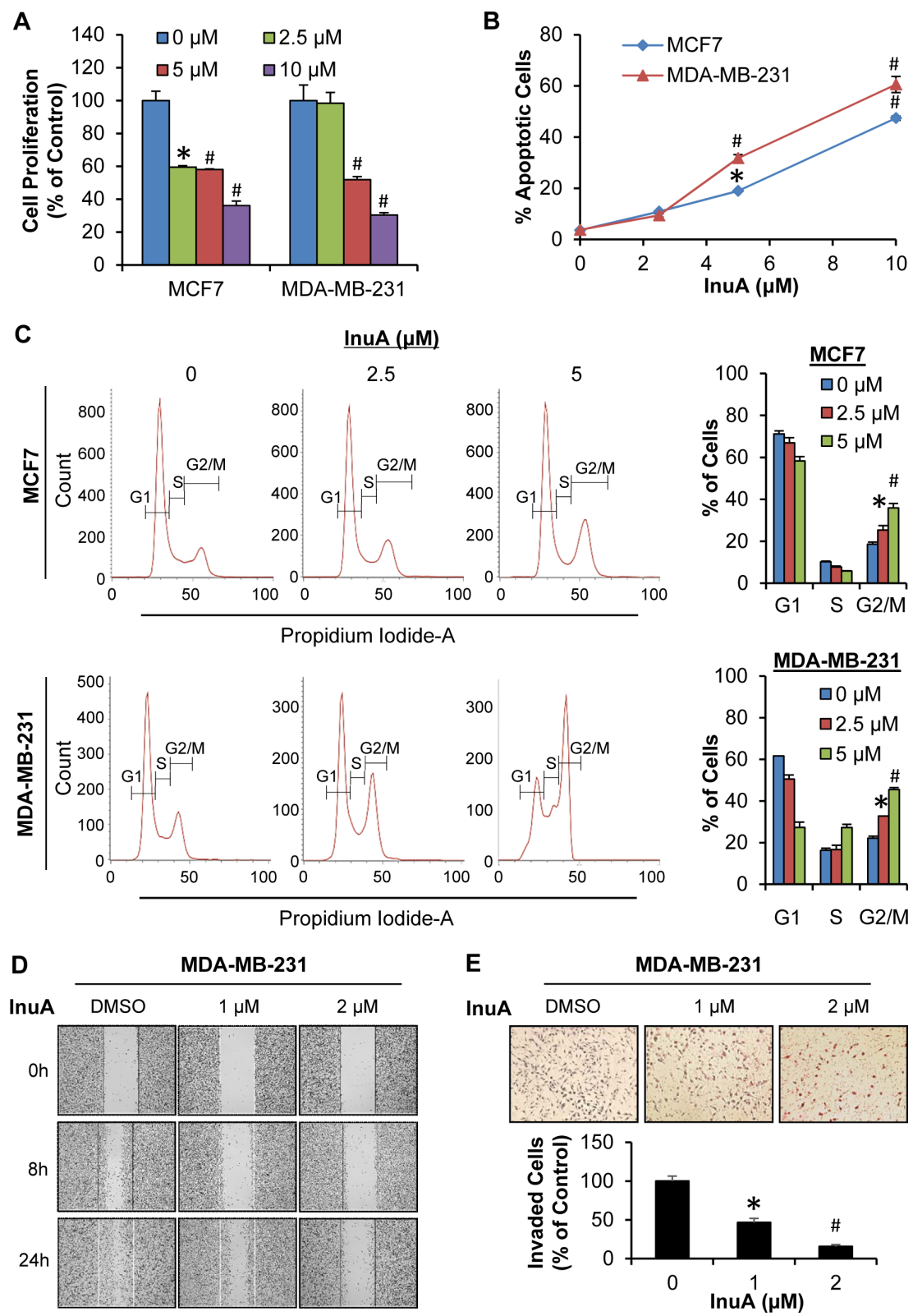

Figure 2: In vitro anti-breast cancer activity of InuA. (A) Antiproliferative effects of InuA. MCF7 and MDA-MB-231 cells were exposed to various concentrations $(0,2.5,5$, and $10 \mu \mathrm{M})$ of InuA for $24 \mathrm{~h}$, followed by measurement of cell proliferation via the BrdUrd assay. The proliferative index is in comparison to untreated cells; (B) Induction of apoptosis by InuA. MCF7 and MDA-MB-231 cells were treated with InuA $(0,2.5,5$, and $10 \mu \mathrm{M})$ for $48 \mathrm{~h}$, followed by measurement of apoptosis using Annexin V assay/flow cytometry; (C) Effects of InuA on cell cycle progression. MCF7 and MDA-MB-231 cells were treated with InuA (0, 2.5 and $5 \mu \mathrm{M})$ for $24 \mathrm{~h}$, followed by determination of cell cycle distribution using flow cytometry; (D\&E) Effects of InuA on metastasis. MDA-MB-231 cells were treated with InuA $(0,1$, and $2 \mu \mathrm{M})$ for $24 \mathrm{~h}$, the migration ability was measured by a wound healing assay (D); and cell invasion ability was measured using a Transwell cell invasion assay $(\mathbf{E})$. All assays were performed in triplicate and repeated three times. $(* P<0.05$ and $\left.{ }^{\#} P<0.01\right)$ DMSO, dimethyl sulfoxide. 
both in vitro and in vivo, contributing to the anticancer activity of the compound. Collectively, Figure 8 depicted the possible mechanisms of action of InuA against breast cancer cells, based on the aforementioned in vitro and in vivo findings.

We first investigated the sensitivity of various normal and cancer cell lines to InuA treatment and this compound exhibited varying cytotoxicity against a broad spectrum of cancer cell lines, regardless of p53 status. Interestingly, the cancer cells containing wild-type p53 (MCF7 and HCT116) showed slightly more sensitive than their corresponding p53 KD or knockout (KO) cell lines (Figure 1), suggesting that the anticancer effects of InuA might not be completely independent of $\mathrm{p} 53$. In p53 wild-type cells, InuA treatment decreased MDM2 expression, resulting in $\mathrm{p} 53$ activation and inducing both

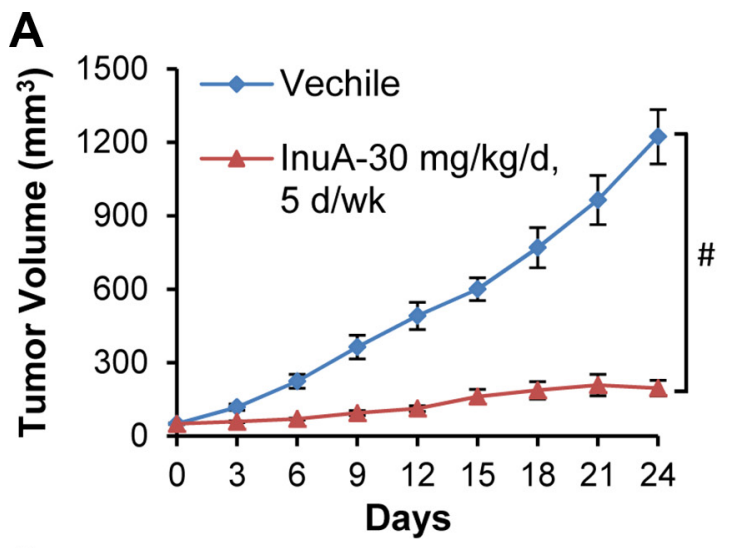

B
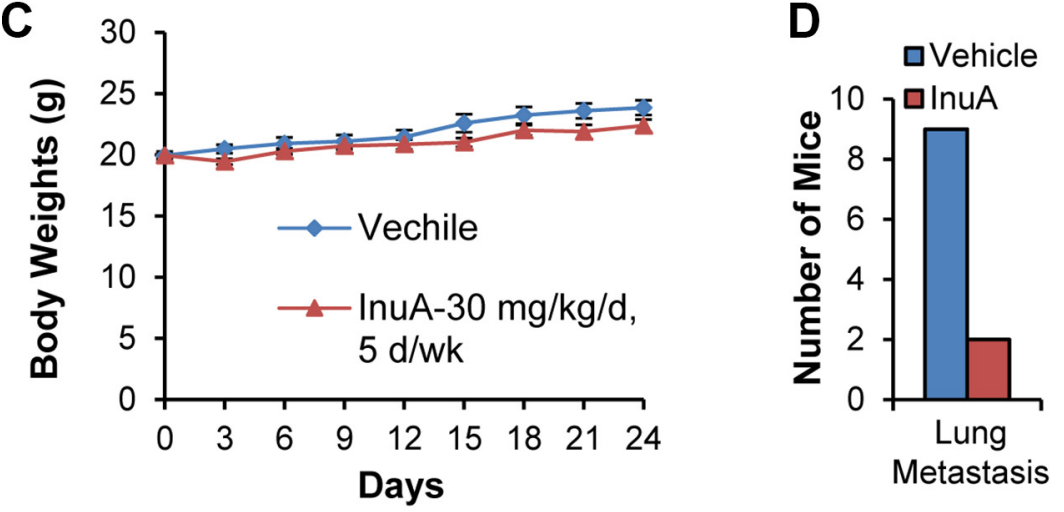

Number of mice

\begin{tabular}{ccc}
\hline Groups & Vehicle & InuA \\
\hline Total & 10 & 10 \\
$\begin{array}{c}\text { Lung } \\
\text { metastasis } \\
\begin{array}{c}\text { No } \\
\text { metastasis }\end{array}\end{array}$ & 9 & 2 \\
\hline
\end{tabular}

E
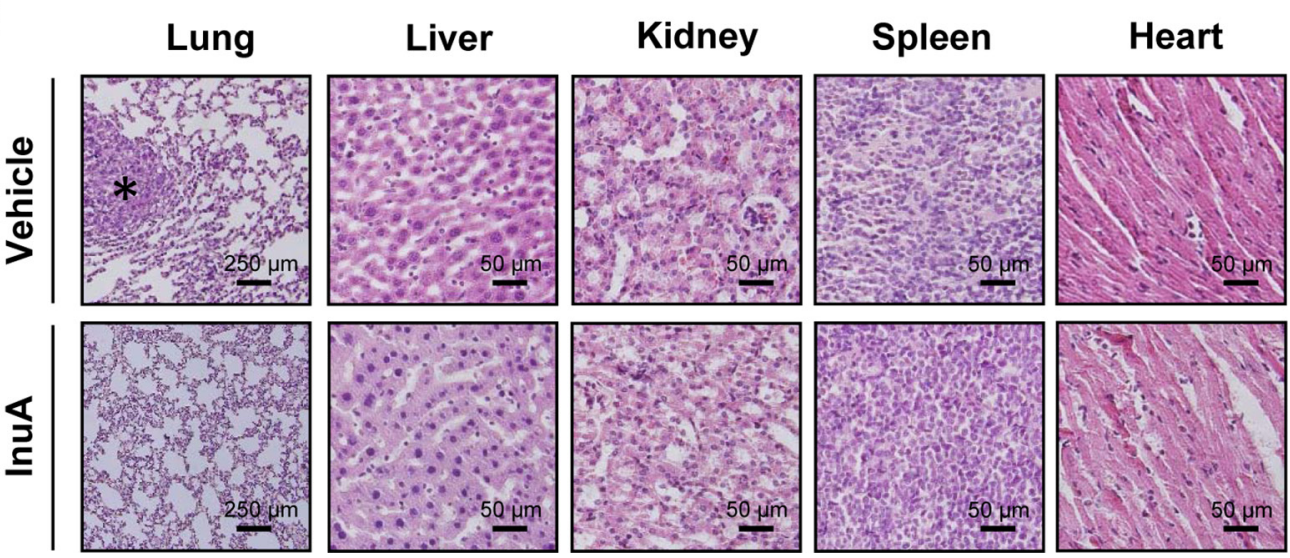

Brain

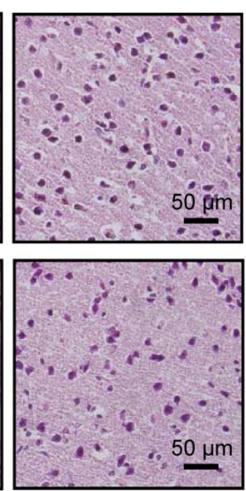

Figure 3: In vivo efficacy of InuA in nude mice bearing MDA-MB-231 orthotopic tumors. (A) MDA-MB-231 cells were implanted orthotopically into the second thoracic mammary fat pad of nude mice. After two weeks, tumor-bearing mice were grouped and treated with InuA by intraperitoneal injection at dose of $30 \mathrm{mg} / \mathrm{kg} / \mathrm{d}, 5 \mathrm{~d} / \mathrm{wk}$ for 24 days. The control mice received vehicle only. (B) At the end of the experiments, representative tumors were removed and photographed. (C) The mice were monitored for changes in body weights as a surrogate marker for toxicity. (D) The mice were examined for tumor metastasis to various organs and the numbers of mice with metastasis to lungs were counted. (E) Various tissues (lung, liver, kidney, spleen, heart, and brain) were carefully removed from mice, and $\mathrm{H} \& \mathrm{E}$ staining of the paraffin sections of these tissues was performed (all images represent serial sections; scale bar, 50 or $250 \mu \mathrm{m}$ ). The black asterisk indicates areas of breast cancer cell invasion. $\left({ }^{\sharp} P<0.01\right)$. 
p53-dependent and -independent cell death; In p53-KD, -mutant, or -null cells, InuA treatment only caused p53independent anticancer effects, leading to higher $\mathrm{IC}_{50}$ values. Of note, all the used breast cell lines were highly sensitive to the treatment of this compound. Two breast cancer cell lines MCF7 (p53 wild-type, ER positive) and MDA-MB-231 (p53 mutant, triple negative) were selected based on their genetic backgrounds for investigating the in vitro activity of InuA and its molecular mechanisms. Both breast cancer cell lines were responsive to the treatment of InuA, showing inhibition in cell proliferation and activation in cell cycle arrest and apoptosis, regardless the status of p53 and ER. Given the excellent anticancer activity of the compound, we further demonstrated its inhibitory effects on NFAT1 and MDM2 in both cell lines. In addition, the changes in various proteins associated with cell proliferation, cell cycle progression, apoptosis,
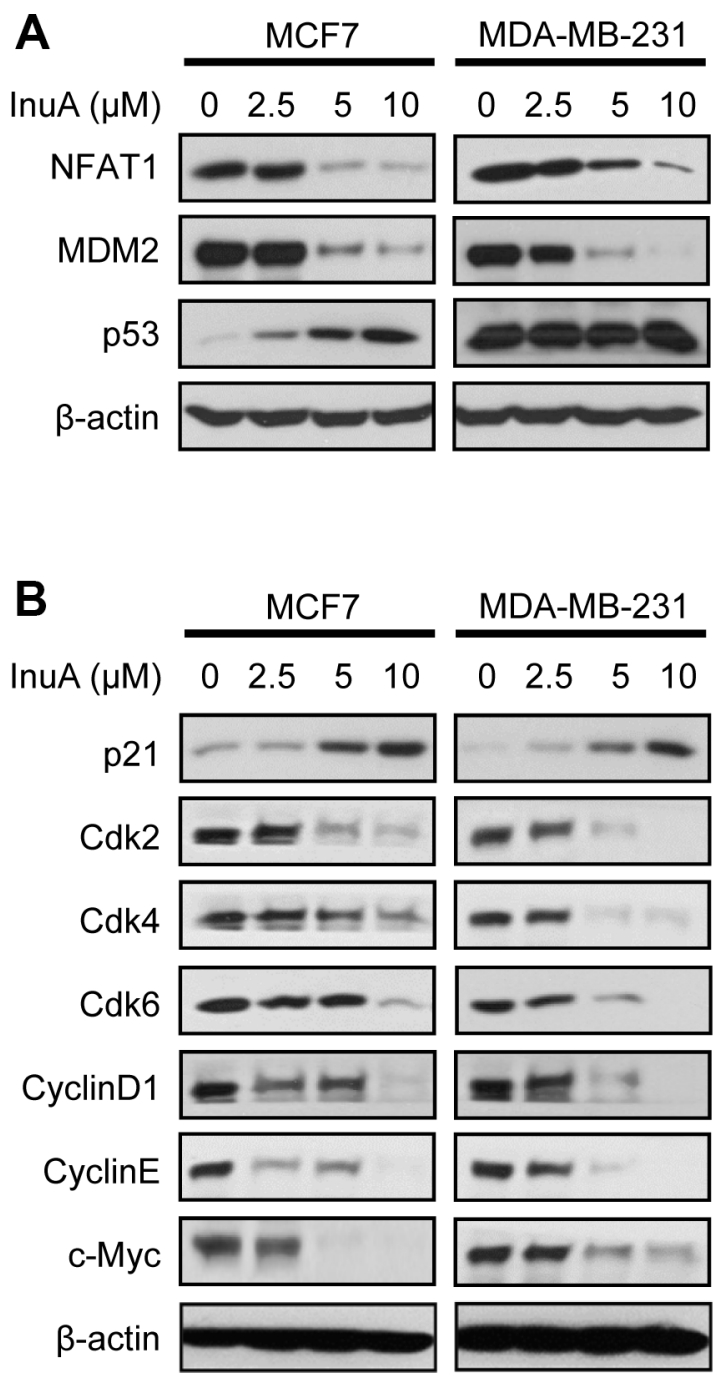

and DNA damage response signaling pathways further corroborated the effects of NFAT1 and MDM2 inhibition. The important role of NFAT1-MDM2 pathway in InuA's anticancer activity has also been validated in both NFAT1 KD and MDM2 KD breast cancer cell lines (both p53 wildtype and mutant). Both NFAT1 KD and MDM2 KD led to decreased sensitivity to InuA, indicating loss of molecular targets (NFAT1 and MDM2) for InuA reduced the target cells' sensitivity. However, further exploration for precise molecular mechanisms responsible for the anticancer activity of InuA also needs to be considered.

To provide more clinically relevant animal models for in vivo testing, we developed MDA-MB-231 orthotopic mouse model, which is better at reflecting the original situation and predicting the efficacy of the drugs than subcutaneous xenograft tumor models. In our studies, InuA showed substantial inhibitory effects on tumor growth.
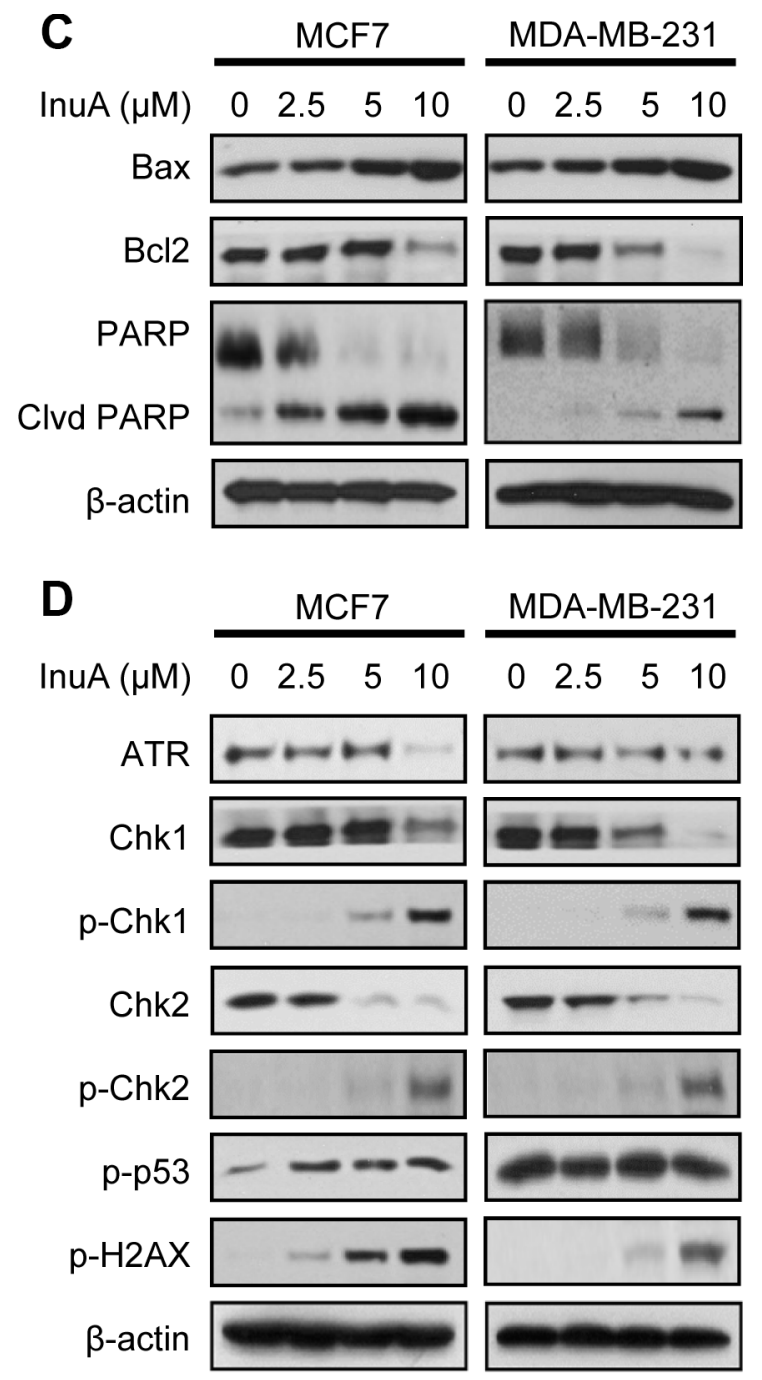

Figure 4: In vitro effects of InuA on NFAT1-MDM2 pathway and on the expression of proteins related to cell cycle progression, apoptosis, and DNA damage response. MCF7 and MDA-MB-231 breast cancer cells were exposed to various concentrations of InuA for $24 \mathrm{~h}$, and the expression of proteins related to (A) NFAT1-MDM2 pathway, (B) cell cycle progression, (C) apoptosis, and (D) DNA damage response were examined by Western blotting assay. All assays were performed in triplicate and repeated three times. NFAT1, nuclear factor of activated T cells 1; MDM2, mouse double minute 2. 
Furthermore, a significant increase in apoptotic cells was observed in InuA-treated tumors, as demonstrated by TUNEL staining, which was consistent with that was observed in in vitro studies. Not surprisingly, the expression patterns of NFAT1, MDM2, and related proteins in InuAtreated tumors were similar as seen in in vitro assays, providing a basis for future biomarker studies for clinical translation of this compound.

With regard to the preventive effects of InuA on breast cancer metastasis, our in vitro studies indicated that the compound at sublethal concentrations effectively inhibited breast cancer cell migration and invasion, as illustrated by wound-healing assay and transwell invasion assay, respectively. The in vivo results obtained from orthotopic mouse model further supported the potent preventive effects of InuA on tumor metastasis. Although InuA exhibited inhibitory effects on cancer cell motility, it could be partially responsible for the reduced lung metastasis in vivo. The effects of InuA on angiogenesis also

need to determine in the future study. More sensitive assays and more clinically relevant metastasis models are expected for further preclinical evaluation and clinical translation of this compound.

Of note, our in vitro and in vivo results showed a favorable safety profile of InuA in the preclinical breast cancer models in the present study. In the cell cytotoxicity assays, we found that the normal cell lines were less sensitive to the treatment of InuA in comparison to the cancer cell lines, indicating that InuA had selective cytotoxicity against cancer cells. In the in vivo efficacy studies, we demonstrated that the average body weights of InuA-treated mice were comparable with that of vehicletreated mice and no organ abnormalities were observed in the histological examinations, implying that InuA did not induce any host toxicity at the effective dose for suppression of breast tumor growth. However, considering that NFAT1 plays an important role in human immune system, which is a relevant point for using NFAT1 inhibitor in the clinics,

A
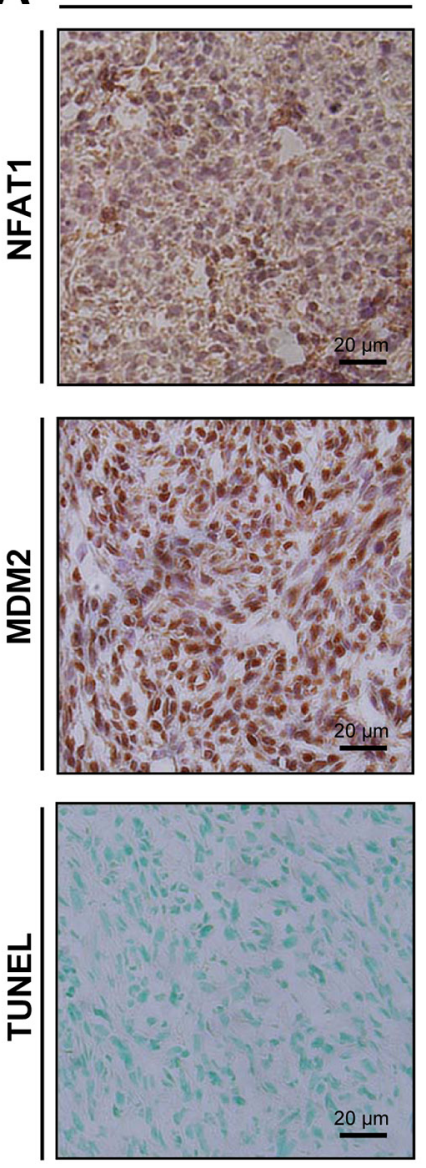

InuA
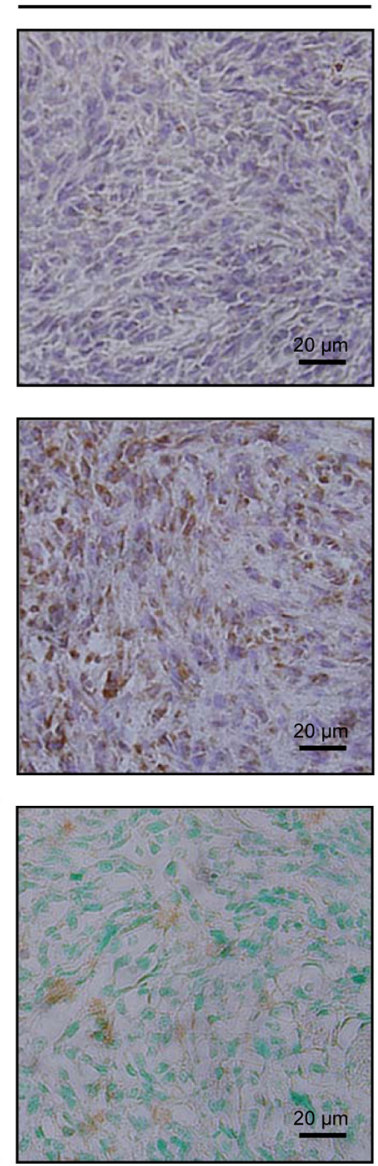

B

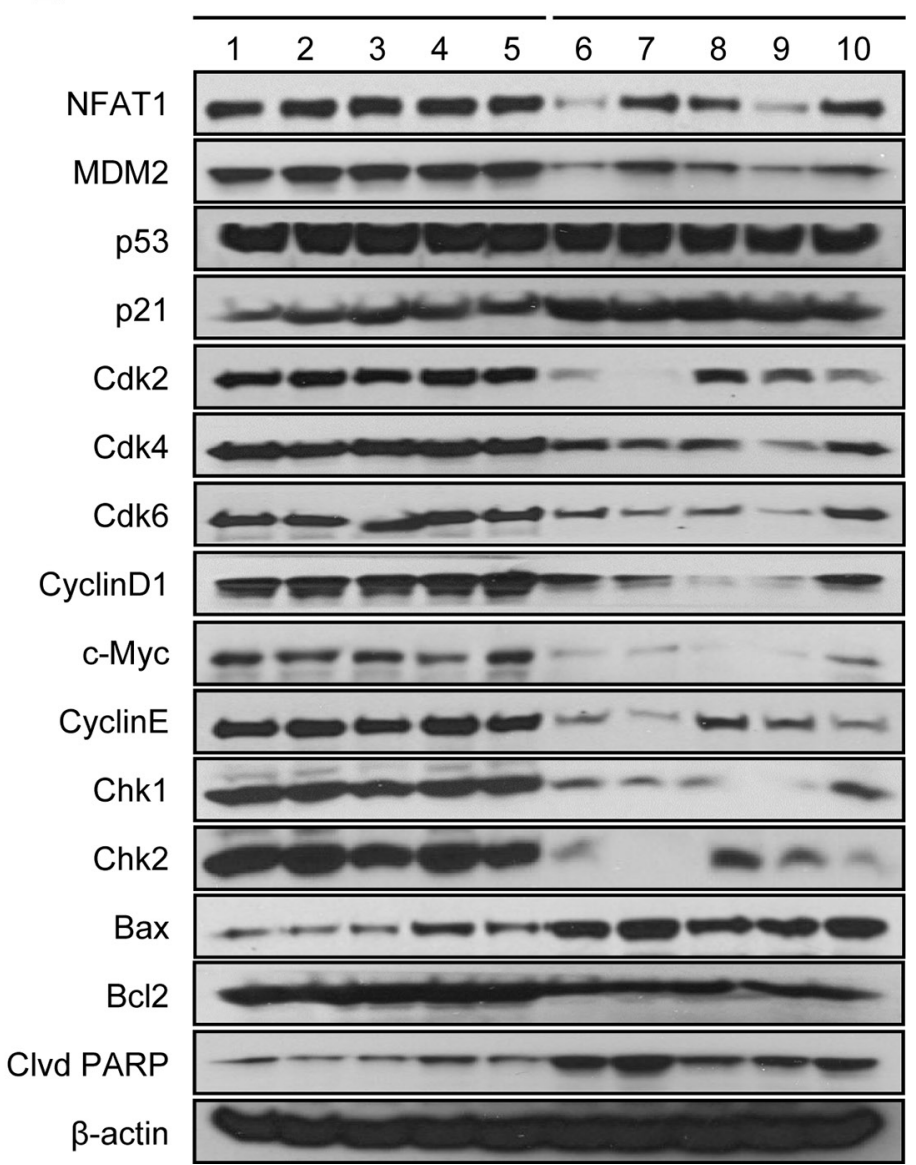

Figure 5: In vivo effects of InuA on NFAT1-MDM2 pathway and on the expression of proteins related to cell cycle progression, apoptosis, and DNA damage response. MDA-MB-231 cells were implanted orthotopically into the second thoracic mammary fat pad of nude mice. After two weeks, tumor-bearing mice were grouped and treated with InuA by intraperitoneal injection at dose of $30 \mathrm{mg} / \mathrm{kg} / \mathrm{d}, 5 \mathrm{~d} / \mathrm{wk}$ for 24 days. The control mice received vehicle only. At the end of the experiments, the orthotopic tumors were carefully removed and analyzed by (A) immunohistochemistry and TUNEL staining (all images represent serial sections; scale bar, $20 \mu \mathrm{m}$ ) and (B) Western blotting assay (Each lane represents an individual mouse tumor sample; control mice: lanes 1-5; InuA-treated mice: lanes 6-10). 
A

MCF7 MDM2 KD

Tet - $-\quad-\quad+\quad+\quad++$

InuA $(\mu \mathrm{M}) \quad 0 \quad 2 \quad 5 \quad 5 \quad 10 \quad 0 \quad 2 \quad 5 \quad 10$

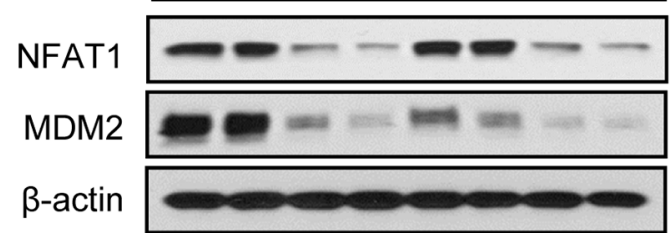

B

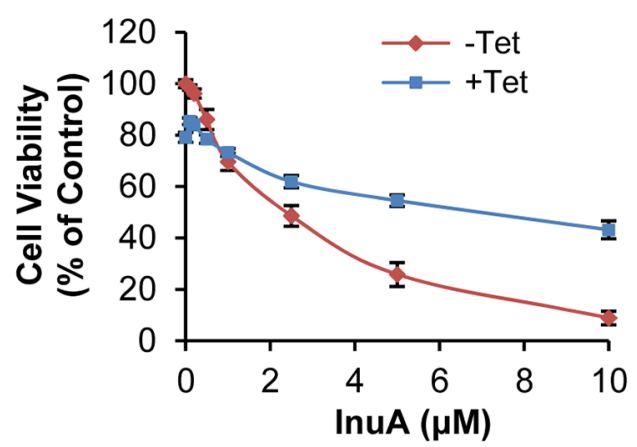

C

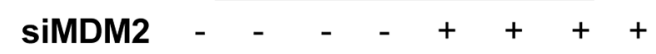

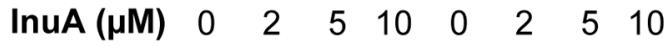

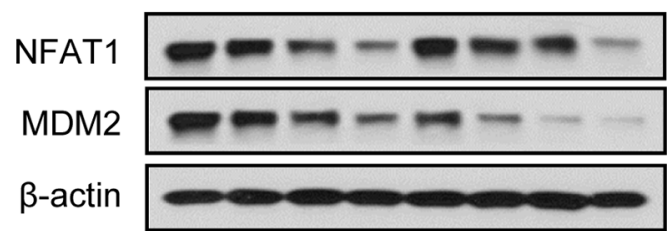

D

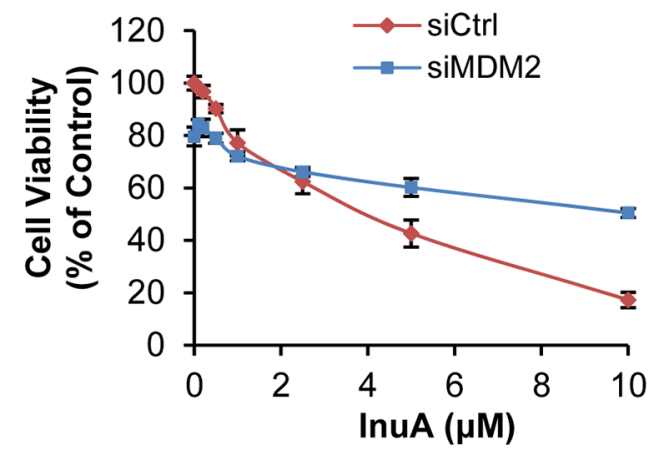

Figure 6: Effects of MDM2 knockdown on InuA-induced cell death. The inducible MDM2 knockdown (KD) MCF7 cells were incubated with (Tet+) or without tetracycline (Tet-) for $24 \mathrm{~h}$, followed by exposure to various concentrations of InuA for (A) $24 \mathrm{~h}$ for examination of expression levels of NFAT1 and MDM2; and (B) $72 \mathrm{~h}$ for cell viability determination. MDA-MB-231 cells were transfected with MDM2 siRNA or the respective control siRNA for $36 \mathrm{~h}$ and then treated with various concentrations of InuA for (C) $24 \mathrm{~h}$ for NFAT1 and MDM2 protein levels; and (D) $72 \mathrm{~h}$ for cell viability. All assays were performed in triplicate.

A

$\begin{array}{rcccccccc}\text { SiNFAT1 } & - & - & - & - & + & + & + & + \\ \text { InuA }(\mu M) & 0 & 2 & 5 & 10 & 0 & 2 & 5 & 10\end{array}$

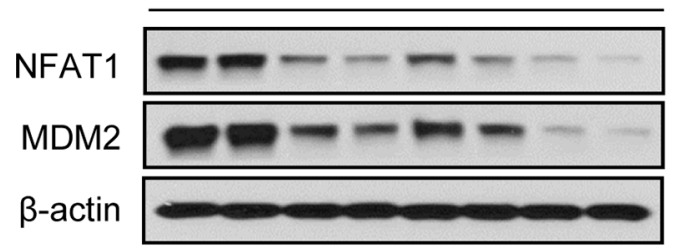

B

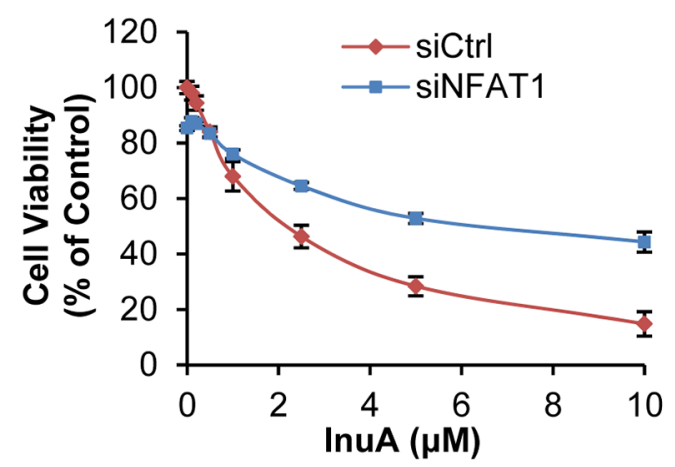

C

$\begin{array}{ccccccccc}\text { SiNFAT1 } & - & - & - & - & + & + & + & + \\ \text { InuA }(\boldsymbol{\mu M}) & 0 & 2 & 5 & 10 & 0 & 2 & 5 & 10\end{array}$

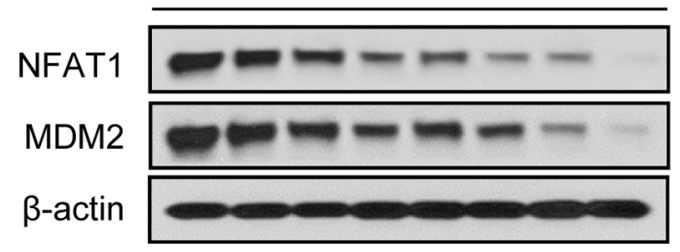

D

MDA-MB-231 NFAT1 KD

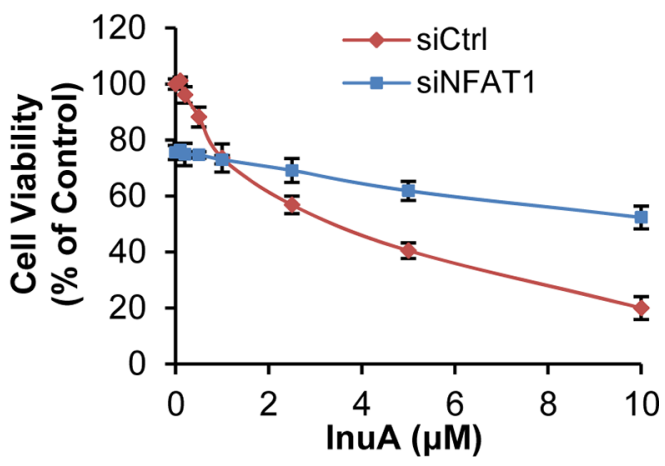

Figure 7: Effects of NFAT1 knockdown on InuA-induced cell death. MCF7 (A, B) and MDA-MB-231 (C, D) breast cancer cells were transfected with NFAT1 siRNA or the respective control siRNA for $36 \mathrm{~h}$ and then treated with various concentrations of InuA for (A, C) $24 \mathrm{~h}$ for examination of expression levels of NFAT1 and MDM2; and (B, D) $72 \mathrm{~h}$ for cell viability determination. All assays were performed in triplicate. 
the potential adverse effects of InuA should be examined in immune cells. In order to get results that are more relevant to the clinics, development of a syngeneic orthotopic model in mice that have immune system is necessary. A thorough understanding of the pharmacological effects and mechanisms of action of InuA is certainly needed for the development of this novel anticancer agent. Further pharmacological and toxicological studies are needed to determine the oral bioavailability, toxicity profile, optimal therapeutic dose and route of the compound. More clinically relevant models of human cancer should be utilized to determine the efficacy, safety, and molecular mechanisms of InuA.

Based on our preliminary data, dual NFAT1-MDM2 inhibitors (JapA and InuA) have desirable efficacy for further preclinical studies and development as clinical candidates. Both compounds are dimeric sesquiterpene lactones and have an identical monomeric fragment. Our initial SAR analyses have indicated that this identical monomeric fragment, especially the $\alpha$-methylene- $\gamma$-lactone group in this fragment, is crucial for their anticancer activity. However, more detailed SAR analyses are still needed to delineate the role of functional groups in the anticancer activity in the future studies.

In summary, the present study has demonstrated that InuA is a novel dual inhibitor of NFAT1-MDM2 pathway and has potent inhibitory effects on breast cancer cell growth and metastasis in vitro and in vivo. These results together suggest that InuA may serve as a potential therapeutic agent for breast cancer treatment and prevention and benefit the patients with advanced disease.

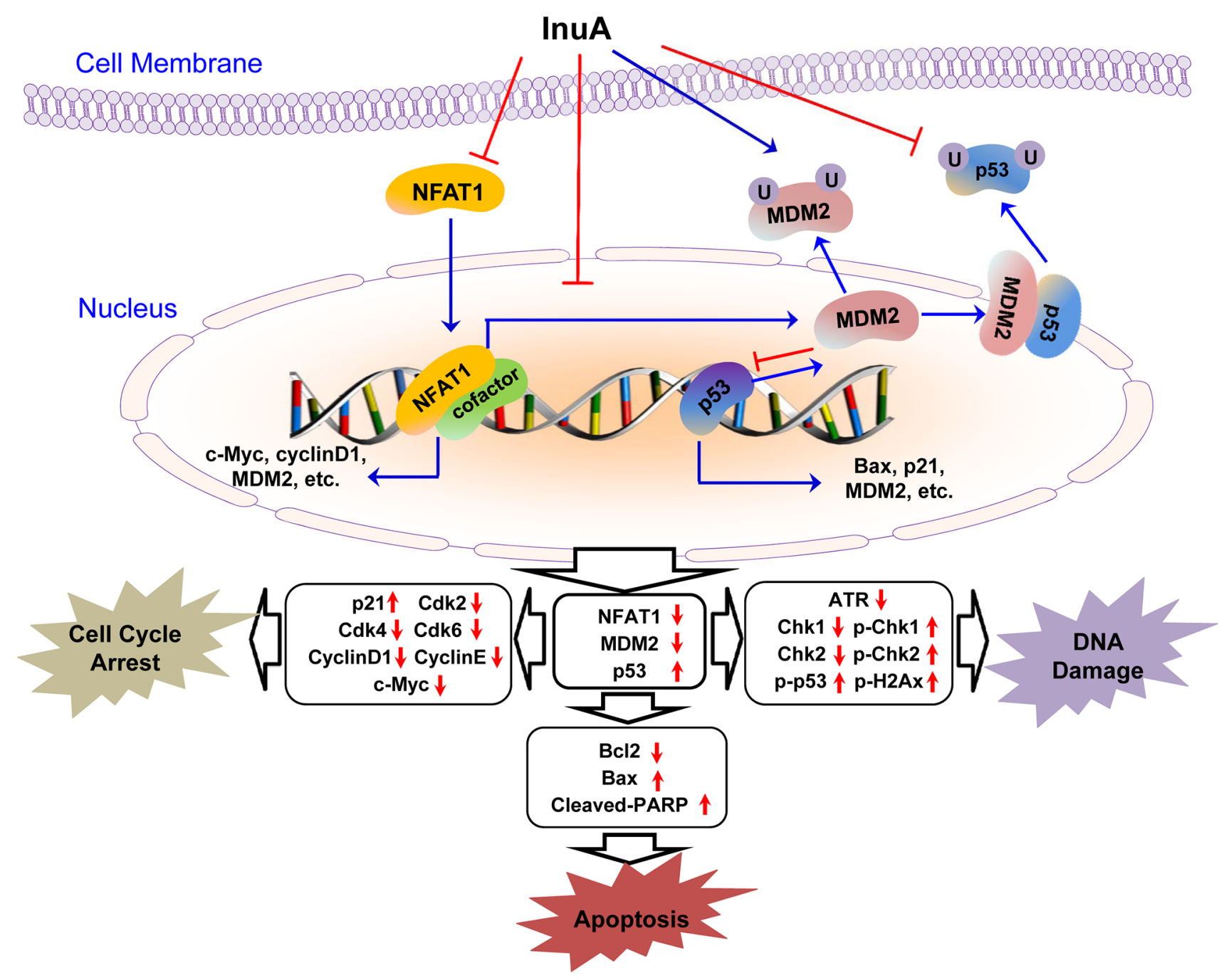

Figure 8: The diagram depicts the possible mechanisms of action of InuA against cancer cells. InuA inhibited cancer cell growth and induced cell cycle arrest and apoptosis by inhibiting the NFAT1-MDM2 pathway and modulating the expression of proteins involved in cell cycle progression, apoptosis, and DNA damage response. ATR, Ataxia telangiectasia and Rad3 related; Bax, Bcl2-Associated X Protein; Bcl2, B-cell lymphoma 2; Cdk2, Cyclin-dependent kinase 2; Cdk4, Cyclin-dependent kinase 4; Cdk6, Cyclindependent kinase 6; Chk1, Checkpoint kinase 1; Chk2, Checkpoint kinase 2; InuA, Inulanolide A; MDM2, mouse double minute 2; NFAT1, nuclear factor of activated T cells 1; PARP, poly ADP ribose polymerase; p-Chk1, phosphorylated Chk1; p-Chk2, phosphorylated Chk2; p-p53, phosphorylated p53; p-H2AX, phosphorylated H2A histone family, member X. 


\section{MATERIALS AND METHODS}

\section{Chemicals and reagents}

All chemicals and solvents used in the present study were of highest grade available. InuA with a purity higher than $95 \%$ was prepared as reported previously [34]. The antibodies against human MDM2 (Ab-2), p21 (Ab-1), and p-H2AX (Ser139) were bought from EMD Chemicals (Gibbstown, NJ, USA). The antibodies against human p53 (DO-1), Cdk2 (M2), Cdk4 (H-22), Cdk6 (C-21), cyclin D1 (DCS-6), cyclin E (HE12), c-Myc (0.N.222), Bax (N-20), Bcl-2 (100), PARP (H-250), Chk1 (G-4), Chk2 (B-4), and ATR (N-19) were purchased from Santa Cruz Biotechnology (Santa Cruz, CA, USA). The antibodies against human p-Chk1 (Ser317), p-Chk2 (Thr68), and p-p53 (Ser15) were obtained from Cell Signaling Technology (Danvers, MA, USA). The anti-human NFAT1 (1/NFAT-1) antibody was sourced from BD Biosciences (San Jose, CA, USA) and the anti-human $\beta$-actin (AC-15) antibody was purchased from Sigma (St. Louis, MO, USA). The goat anti-mouse $\operatorname{IgG}(\mathrm{H}+\mathrm{L})$ and goat anti-rabbit $\operatorname{IgG}(\mathrm{H}+\mathrm{L})$ antibodies were bought from Bio-Rad (Hercules, CA, USA). The NFAT1 and MDM2 siRNA pool and control siRNA pool were obtained from Thermo Scientific (Rockford, IL, USA).

\section{Cell lines and culture conditions}

Human normal and cancer cell lines were obtained from American Type Culture Collection (Rockville, MD, USA). All cell culture media mentioned below were supplemented with $10 \%$ fetal bovine serum (FBS) (Atlanta Biologicals, Lawrenceville, GA, USA) and 1\% penicillin/ streptomycin (Corning, Manassas, VA, USA), except for those indicated otherwise. Human breast cancer MCF7, MCF7 p53 KD, MDA-MB-468, and MDA-MB-231 cells and human breast epithelial MCF10A cells were cultured as described previously $[21,26]$. Human prostate cancer PC3 cells were maintained in Ham's F12 medium containing $2 \mathrm{mM}$ L-glutamine, LNCaP cells were cultured in RPMI 1640 media containing $2 \mathrm{mM}$ L-glutamine, $10 \mathrm{mM}$ HEPES, $1 \mathrm{mM}$ sodium pyruvate, glucose $(4.5 \mathrm{mg} / \mathrm{mL})$, and sodium bicarbonate $(1.5 \mathrm{mg} / \mathrm{mL})$, and DU145 cells were cultured in RPMI 1640 medium. Human lung cancer A549 cells were grown in Ham's F12 medium and H385 cells were cultured in RPMI 1640 medium. Human pancreatic cancer HPAC cells were grown in DMEM/Ham's F12 media containing $1.2 \mathrm{~g} / \mathrm{L}$ sodium bicarbonate, $2.5 \mathrm{mM}$ L-glutamine, $15 \mathrm{mM}$ HEPES, and $0.5 \mathrm{mM}$ sodium pyruvate supplemented with $2 \mu \mathrm{g} / \mathrm{mL}$ insulin, $5 \mu \mathrm{g} / \mathrm{mL}$ transferrin, $40 \mathrm{ng} / \mathrm{mL}$ hydrocortisone, $10 \mathrm{ng} / \mathrm{mL}$ epidermal growth factor, and 5\% FBS, Panc-1 cells were cultured with RPMI 1640 containing $1 \mathrm{mM}$ HEPES buffer, $25 \mu \mathrm{g} / \mathrm{mL}$ gentamicin, $1.5 \mathrm{~g} / \mathrm{L}$ sodium bicarbonate, and $0.25 \mu \mathrm{g} / \mathrm{mL}$ amphotericin $\mathrm{B}$, and BxPC3 were grown in RPMI 1640 medium. Human colon cancer HCT116 and HCT116 p53KO (HCT116 p53 $3^{--}$) cells were grown in McCoy's 5A medium. Human osteosarcoma U2OS cells were maintained in DMEM medium. Human ovarian cancer SKOV-3 cells were maintained in McCoy's 5A medium and OVCAR-3 cells were cultured in RPMI 1640 medium supplemented with $20 \% \mathrm{FBS}, 10 \mathrm{mM}$ of sodium pyruvate, $10 \mathrm{mM}$ of HEPES, $10 \mathrm{mg} / \mathrm{L}$ of bovine insulin, and $4.5 \mathrm{~g} / \mathrm{L}$ of glucose. Human liver cancer HepG2 and Hep3B cells were grown in DMEM medium. Human glioma U87MG cells were grown in Eagle's minimum essential medium (EMEM). Human embryonic kidney HEK293 cells were grown in DMEM medium. The inducible MDM2 KD MCF7 cell line was established previously $[21,26]$ and was grown in DMEM medium containing $0.5 \mu \mathrm{g} / \mathrm{mL}$ puromycin (Sigma, St. Louis, MO, USA).

\section{Assays for in vitro anticancer activity of InuA}

The assays for the effects of InuA on cell viability (MTT assay) [21,26], cell proliferation [bromodeoxyuridine (BrdU) incorporation assay] [21, 26], cell cycle progression $[21,26]$, cell apoptosis (Annexin V-FITC apoptosis detection kit) [21, 26], cell migration (wound healing assay) [21, 35], and cell invasion (transwell invasion assay) [36] were performed as described in our previous studies.

In brief, the cells were seeded in 96-well plates (3-4 $\times 10^{3}$ cells/well) for $24 \mathrm{~h}$ and exposed to various concentrations of InuA $(0-50 \mu \mathrm{M})$ for another $72 \mathrm{~h}$ for the MTT assay. For BrdU incorporation assay, the cells (5-8 $\times$ $10^{3}$ cells/well) in 96-well plates were treated with various concentrations of InuA $(0,2.5,5$, and $10 \mu \mathrm{M})$ for $14 \mathrm{~h}$, and then incubated with the BrdU for another $10 \mathrm{~h}$. To detect cell apoptosis, the cells in 6-well plates $\left(2-3 \times 10^{5}\right.$ cells/well $)$ were exposed to various concentrations of InuA $(0,2.5,5$, and $10 \mu \mathrm{M}$ ) for $48 \mathrm{~h}$. The cells were then harvested and resuspended in Annexin V binding buffer and incubated with Annexin V-FITC and propidium iodide (Sigma, St. Louis, MO, USA). Both early apoptosis and later apoptosis were determined by flow cytometry (BD Biosciences, San Jose, CA, USA). To analyze the cell cycle distribution, the cells in 6-well plates $\left(2-3 \times 10^{5}\right.$ cells/well $)$ were treated with various concentrations of InuA $(0,2.5$, and $5 \mu \mathrm{M})$ for 24 h. Then the cells were fixed at $4^{\circ} \mathrm{C}$ overnight, incubated with RNase (Sigma, St. Louis, MO, USA), and stained with propidium iodide for flow cytometry analysis.

To determine the effects of InuA on cell migration, the monolayer of MDA-MB-231 cells was grown to confluence in 6-well plates and scratched in each well using a pipette tip. The cells were then treated with InuA ( 1 or $2 \mu \mathrm{M})$, and five fields of each wound were monitored and photographed at 0 , 8 , and $24 \mathrm{~h}$. To determine the effects of InuA on cell invasion, the cells were seeded on the upper well of Boyden chamber $\left(1-2 \times 10^{4}\right.$ cells/well) and exposed to InuA $(1$ or $2 \mu \mathrm{M})$ for $24 \mathrm{~h}$. The cells on the upper surface were then removed by wiping with a cotton swab and the cells adhering to the filter were stained with Mayer's Hematoxylin and Eosin solution and photographed under a phase-contrast Olympus microscope (Olympus America Inc, PA, USA). The positive staining area was measured using image analysis software. 


\section{Western blotting analysis}

In brief, the cells in 6-cm dishes $\left(3-4 \times 10^{5}\right.$ cells/ dish) were exposed to various concentrations of InuA ( 0 , $2.5,5$, and $10 \mu \mathrm{M}$ ) for $24 \mathrm{~h}$. Then the cells were lysed in NP-40 lysis buffer containing a protease inhibitor mixture (Sigma, St. Louis, MO, USA). The tumor tissue samples were homogenized in NP-40 lysis buffer and centrifuged for the supernatants. Both cell and tumor tissue samples were quantified and subjected to Western blotting analysis for the expression levels of various proteins using the methods as described previously $[21,26]$.

\section{NFAT1 and MDM2 silencing}

MCF-7 and MDA-MB-231 cells $\left(2 \times 10^{5}\right.$ cells/dish $)$ were transfected with NFAT1 or MDM2 siRNA pool or control siRNA pool as described previously [21, 33]. After $36 \mathrm{~h}$ of transfection, cells were treated with InuA $(0,2,5$, and $10 \mu \mathrm{M}$ ) for $24 \mathrm{~h}$. The cell lysates were used for Western blotting analysis. For cell viability assay, the transfected cells were seeded in 96 -well plates $\left(3 \times 10^{3}\right.$ cells/well $)$ and treated with InuA $(0-10 \mu \mathrm{M})$ for $72 \mathrm{~h}$ for MTT assay.

\section{MDA-MB-231 orthotopic model and in vivo efficacy study of InuA}

The animal protocols were approved by the Institutional Animal Use and Care Committee of Texas Tech University. Female athymic nude mice (nu/nu, 4-6 weeks) were purchased from Charles River Laboratories International, Inc. (Wilmington, MA, USA). After anesthesia, MDA-MB-231 cells $\left(1 \times 10^{6}\right.$ cell/mouse $)$ were implanted into the second thoracic mammary fat pad. After two weeks, tumor-bearing mice were divided into control and treatment groups (10 mice/group). InuA was dissolved in PEG400:ethanol:saline (57.1:14.3:28.6, v/v/v) and administered by intraperitoneal injection at a dose of $30 \mathrm{mg} / \mathrm{kg} / \mathrm{d}, 5 \mathrm{~d} / \mathrm{wk}$ for 24 days. The control group received the vehicle only. All mice were monitored for activity, physical condition, body weights, and tumor growth during the treatment period. The tumor volume $\left(\mathrm{mm}^{3}\right)$ was calculated by the formula: $\left(a \times b^{2}\right) / 2$, where " $a$ " is the long diameter $(\mathrm{cm})$ and " $\mathrm{b}$ " is the short diameter $(\mathrm{cm})$. At the end of the experiments, all mice were examined for tumor metastasis to lungs. Various tissues (lungs, brain, heart, liver, spleen, and kidneys) were removed and processed for Hematoxylin and Eosin (H\&E) staining, and orthotopic tumors were removed and processed for Western blotting analysis, immunohistochemistry, and TUNEL assay.

\section{Immunohistochemistry, TUNEL staining, and H\&E staining}

In brief, tumors and various tissues from the mice bearing orthotopic tumors were fixed in $10 \%$ formalin and embedded in paraffin. Then the tumor and tissue sections $(5 \mu \mathrm{m})$ were prepared and deparaffinized in xylenes, rehydrated, and washed with PBS. The immunohistochemistry examination of NFAT1 and MDM2 was performed using the biotinylated anti-human NFAT1 and MDM2 antibodies (diluted 1:50 in 5\% BSA in PBS), respectively $[21,26,36]$. Sections were counterstained with hematoxylin and mounted. The TUNEL assays were performed as described previously [21, 26, 36]. Briefly, tumor sections were incubated with proteinase $\mathrm{K}$ for $15 \mathrm{~min}$, and then DNA breaks were labeled with terminal deoxytransferase (TdT) in a humidified chamber for $5 \mathrm{~min}$. The sections were then incubated with $50 \mu \mathrm{L}$ of biotinylated BrdU antibody for $1 \mathrm{~h}$. Both the immunohistochemistry and TUNEL staining were developed with streptavidinconjugated HRP and 3,3'-diaminobenzidene (HRP substrate). For H\&E staining, tissue sections were stained in Mayer's Hematoxylin for 10 min and then stained with Eosin for $1 \mathrm{~min}$. All the slides were analyzed and viewed under a phase-contrast Olympus microscope (Olympus America Inc., Central Valley, PA).

\section{Statistical analysis}

Quantitative data were presented as mean \pm SEM from at least three independent experiments. Statistical significances were determined using Student's $t$-test and $P<0.05$ was considered to be statistically significant.

\section{ACKNOWLEDGMENTS AND FUNDING}

This work is supported by American Cancer Society (ACS) grant RSG-15-009-01-CDD (to W.W.). This work was also supported by the National Institutes of Health (NIH) grant R01 CA186662 (to R.Z.) and CA102514 (to R.A.). The content is solely the responsibility of the authors, and do not necessarily represent the official views of the National Institutes of Health.

\section{CONFLICTS OF INTEREST}

The authors declare no conflicts of interest.

\section{REFERENCES}

1. Siegel RL, Miller KD, Jemal A. Cancer statistics, 2016. CA Cancer J Clin. 2016; 66:7-30.

2. DeSantis CE, Fedewa SA, Goding Sauer A, Kramer JL, Smith RA, Jemal A. Breast cancer statistics, 2015: Convergence of incidence rates between black and white women. CA Cancer J Clin. 2016; 66:31-42.

3. Ward EM, DeSantis CE, Lin CC, Kramer JL, Jemal A, Kohler B, Brawley OW, Gansler T. Cancer statistics: Breast cancer in situ. CA Cancer J Clin. 2015; 65:481-495.

4. Dent S, Oyan B, Honig A, Mano M, Howell S. HER2targeted therapy in breast cancer: a systematic review of neoadjuvant trials. Cancer Treat Rev. 2013; 39:622-631. 
5. Johnston SR. Targeted Combinations for Hormone ReceptorPositive Advanced Breast Cancer: Who Benefits? J Clin Oncol. 2015.

6. Prat A, Adamo B, Cheang MC, Anders CK, Carey LA, Perou CM. Molecular characterization of basal-like and non-basal-like triple-negative breast cancer. Oncologist. 2013; 18:123-133.

7. Palma G, Frasci G, Chirico A, Esposito E, Siani C, Saturnino C, Arra C, Ciliberto G, Giordano A, D'Aiuto M. Triple negative breast cancer: looking for the missing link between biology and treatments. Oncotarget. 2015; 6:26560-26574. doi: 10.18632/oncotarget.5306.

8. Anders CK, Zagar TM, Carey LA. The management of earlystage and metastatic triple-negative breast cancer: a review. Hematol Oncol Clin North Am. 2013; 27:737-749, viii.

9. Zhang J, Fan M, Xie J, Wang Z, Wang B, Zhang S, Wang L, Cao J, Tao Z, Li T, Hu X. Chemotherapy of metastatic triple negative breast cancer: Experience of using platinumbased chemotherapy. Oncotarget. 2015; 6:43135-43143. doi: 10.18632/oncotarget.5654.

10. Bouska A, Eischen CM. Murine double minute 2: p53independent roads lead to genome instability or death. Trends Biochem Sci. 2009; 34:279-286.

11. Nag S, Qin J, Srivenugopal KS, Wang M, Zhang R. The MDM2-p53 pathway revisited. J Biomed Res. 2013; 27:254-271.

12. Bohlman S, Manfredi JJ. p53-independent effects of Mdm2. Subcell Biochem. 2014; 85:235-246.

13. Santarius T, Shipley J, Brewer D, Stratton MR, Cooper CS. A census of amplified and overexpressed human cancer genes. Nat Rev Cancer. 2010; 10:59-64.

14. Van den Broek AJ, Broeks A, Horlings HM, Canisius SV, Braaf LM, Langerod A, Van't Veer LJ, Schmidt MK. Association of the germline TP53 R72P and MDM2 SNP309 variants with breast cancer survival in specific breast tumor subgroups. Breast Cancer Res Treat. 2011; 130:599-608.

15. Boersma BJ, Howe TM, Goodman JE, Y fantis HG, Lee DH, Chanock SJ, Ambs S. Association of breast cancer outcome with status of p53 and MDM2 SNP309. J Natl Cancer Inst. 2006; 98:911-919.

16. Yu Q, Li Y, Mu K, Li Z, Meng Q, Wu X, Wang Y, Li L. Amplification of Mdmx and overexpression of MDM2 contribute to mammary carcinogenesis by substituting for p53 mutations. Diagn Pathol. 2014; 9:71.

17. Park HS, Park JM, Park S, Cho J, Kim SI, Park BW. Subcellular localization of Mdm2 expression and prognosis of breast cancer. Int J Clin Oncol. 2014; 19:842-851.

18. Chen X, Qiu J, Yang D, Lu J, Yan C, Zha X, Yin Y. MDM2 promotes invasion and metastasis in invasive ductal breast carcinoma by inducing matrix metalloproteinase-9. PLoS One. 2013; 8:e78794.

19. Maglic D, Zhu S, Fry EA, Taneja P, Kai F, Kendig RD, Sugiyama T, Miller LD, Willingham MC, Inoue K. Prognostic value of the hDMP1-ARF-Hdm2-p53 pathway in breast cancer. Oncogene. 2013; 32:4120-4129.
20. Yang JY, Zong CS, Xia W, Wei Y, Ali-Seyed M, Li Z, Broglio K, Berry DA, Hung MC. MDM2 promotes cell motility and invasiveness by regulating E-cadherin degradation. Mol Cell Biol. 2006; 26:7269-7282.

21. Wang W, Qin JJ, Voruganti S, Srivenugopal KS, Nag S, Patil S, Sharma H, Wang MH, Wang H, Buolamwini JK, Zhang R. The pyrido[b]indole MDM2 inhibitor SP-141 exerts potent therapeutic effects in breast cancer models. Nat Commun. 2014; 5:5086.

22. Vassilev LT, Vu BT, Graves B, Carvajal D, Podlaski F, Filipovic Z, Kong N, Kammlott U, Lukacs C, Klein C, Fotouhi N, Liu EA. In vivo activation of the p53 pathway by small-molecule antagonists of MDM2. Science. 2004; 303:844-848.

23. Issaeva N, Bozko P, Enge M, Protopopova M, Verhoef LG, Masucci M, Pramanik A, Selivanova G. Small molecule RITA binds to p53, blocks p53-HDM-2 interaction and activates p53 function in tumors. Nat Med. 2004; 10:1321-1328.

24. Shangary S, Qin D, McEachern D, Liu M, Miller RS, Qiu S, Nikolovska-Coleska Z, Ding K, Wang G, Chen J, Bernard D, Zhang J, Lu Y, Gu Q, et al. Temporal activation of $\mathrm{p} 53$ by a specific MDM2 inhibitor is selectively toxic to tumors and leads to complete tumor growth inhibition. Proc Natl Acad Sci U S A. 2008; 105:3933-3938.

25. Wang W, Qin JJ, Voruganti S, Wang MH, Sharma H, Patil S, Zhou J, Wang H, Mukhopadhyay D, Buolamwini JK, Zhang R. Identification of a new class of MDM2 inhibitor that inhibits growth of orthotopic pancreatic tumors in mice. Gastroenterology. 2014; 147:893-902.

26. Qin JJ, Wang W, Voruganti S, Wang H, Zhang WD, Zhang R. Identification of a new class of natural product MDM2 inhibitor: In vitro and in vivo anti-breast cancer activities and target validation. Oncotarget. 2015; 6:2623-2640. doi: 10.18632/oncotarget.3098.

27. Ding Q, Zhang Z, Liu JJ, Jiang N, Zhang J, Ross TM, Chu XJ, Bartkovitz D, Podlaski F, Janson C, Tovar C, Filipovic ZM, Higgins B, et al. Discovery of RG7388, a potent and selective p53-MDM2 inhibitor in clinical development. J Med Chem. 2013; 56:5979-5983.

28. Rew Y, Sun D. Discovery of a small molecule MDM2 inhibitor (AMG 232) for treating cancer. J Med Chem. 2014; 57:6332-6341.

29. Zhang X, Zhang Z, Cheng J, Li M, Wang W, Xu W, Wang H, Zhang R. Transcription factor NFAT1 activates the mdm2 oncogene independent of p53. J Biol Chem. 2012; 287: 30468-30476.

30. Kaunisto A, Henry WS, Montaser-Kouhsari L, Jaminet SC, Oh EY, Zhao L, Luo HR, Beck AH, Toker A. NFAT1 promotes intratumoral neutrophil infiltration by regulating IL8 expression in breast cancer. Mol Oncol. 2015; 9:1140-1154.

31. Quang CT, Leboucher S, Passaro D, Fuhrmann L, Nourieh M, Vincent-Salomon A, Ghysdael J. The calcineurin/NFAT pathway is activated in diagnostic breast cancer cases and is essential to survival and metastasis of mammary cancer cells. Cell Death Dis. 2015; 6:e1658. 
32. Qin JJ, Nag S, Wang W, Zhou J, Zhang WD, Wang H, Zhang R. NFAT as cancer target: Mission possible? Biochim Biophys Acta. 2014; 1846:297-311.

33. Qin JJ, Wang W, Voruganti S, Wang H, Zhang WD, Zhang R. Inhibiting NFAT1 for breast cancer therapy: New insights into the mechanism of action of MDM2 inhibitor JapA. Oncotarget. 2015; 6:33106-33119. doi: 10.18632/ oncotarget.5851.

34. Zhu JX, Qin JJ, Jin HZ, Zhang WD. Japonicones Q-T, four new dimeric sesquiterpene lactones from Inula japonica Thunb. Fitoterapia. 2013; 84:40-46.
35. Wang W, Zhang X, Qin JJ, Voruganti S, Nag SA, Wang MH, Wang H, Zhang R. Natural product ginsenoside 25-OCH3PPD inhibits breast cancer growth and metastasis through down-regulating MDM2. PLoS One. 2012; 7:e41586.

36. Wang W, Cheng J, Qin JJ, Voruganti S, Nag S, Fan J, Gao Q, Zhang R. RYBP expression is associated with better survival of patients with hepatocellular carcinoma (HCC) and responsiveness to chemotherapy of HCC cells in vitro and in vivo. Oncotarget. 2014; 5:11604-11619. doi: 10.18632/ oncotarget.2598. 